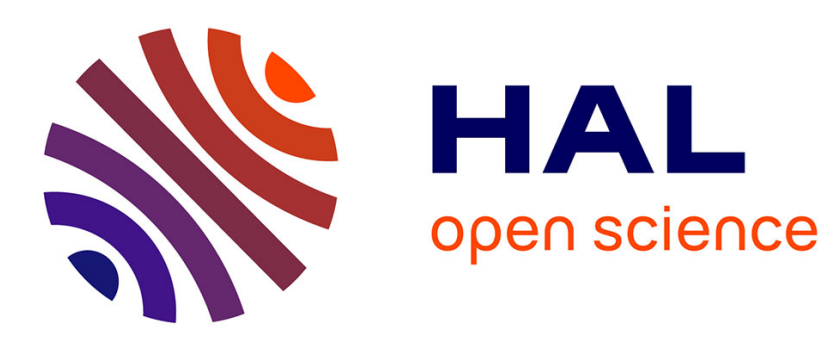

\title{
Application of the indirect Fourier transform method to a study of zeolite nucleation
}

O. Regev, Y. Cohen, E. Kehat, Y. Talmon

\section{To cite this version:}

O. Regev, Y. Cohen, E. Kehat, Y. Talmon. Application of the indirect Fourier transform method to a study of zeolite nucleation. Journal de Physique IV Proceedings, 1993, 03 (C8), pp.C8-397-C8-400. 10.1051/jp4:1993883 . jpa-00252314

\section{HAL Id: jpa-00252314 https://hal.science/jpa-00252314}

Submitted on 1 Jan 1993

HAL is a multi-disciplinary open access archive for the deposit and dissemination of scientific research documents, whether they are published or not. The documents may come from teaching and research institutions in France or abroad, or from public or private research centers.
L'archive ouverte pluridisciplinaire HAL, est destinée au dépôt et à la diffusion de documents scientifiques de niveau recherche, publiés ou non, émanant des établissements d'enseignement et de recherche français ou étrangers, des laboratoires publics ou privés. 


\title{
Application of the indirect Fourier transform method to a study of zeolite nucleation
}

\author{
O. REGEV $^{(1)}$, Y. COHEN, E. KEHAT and Y. TALMON \\ Department of Chemical Engineering, Technion Israel Institute of Technology, Haifa 32000, Israel
}

\begin{abstract}
The nucleation events of synthesis reactions of ZSM5 and Na-A zeolites were studied, with particular emphasis on the role of organic template, TPA (tetrapropylammonium), in the ZSM5 synthesis. Qualitative evaluation of the structural units was obtained by Small-Angle X-ray Scattering (SAXS) measurements which were analyzed using an indirect Fourier transform method. In the presence of organic cation TPA ${ }^{+}$in the ZSM5 synthesis we found globular structural units, 5 $\mathrm{nm}$ in diameter, which aggregate to elongated bodies $44 \mathrm{~nm}$ long. These results suggest that the zeolite ZSM5 building blocks are globular structural units, $5 \mathrm{~nm}$ in diameter, containing silica, alumina, organic cation and water, which fuse together to produce elongated aggregates that may compose the final unit cell. We found that the Na-A zeolite follows nucleation via $1 \mathrm{~nm}$ globular particles, which suggests that the existence of globular structural units in the nucleation of zeolites is a general phenomenon.
\end{abstract}

\section{Introduction}

The synthesis of most zeolites begins by aging of silica, alumina and water, generally with a templating agent, to produce a silica sol (termed 'mother liquor') containing monomeric and oligomeric silicates. These silicates react with aluminate anions to produce an aluminosilicate gel. The gel dissolves during the reaction, releasing mostly silicate ions, which can slowly react to produce a porous crystalline zeolite containing straight and sinusoidal channels which intersect at junctions.

Nucleation from solution involves a limited number of ZSM5 or Na-A nuclei that are formed at the expense of the amorphous aluminum-rich phase. Reaction rate is slow and is governed by the dissolution of silica. The induction period of ZSM5 and Na-A zeolites takes about 30 hours and 4 minutes respectively. The atom-atom interaction ${ }^{1}$ and the phase behavior ${ }^{2}$ in the nucleation stage of the ZSM5 synthesis reaction have been studied. However, a clear and general picture of the nucleation process was not presented. In this work we investigated the microstructural evolution in the nucleation stage of the zeolites ZSM5 and Na-A.

(1) present address: Department of Chemical Engineering, Ben-Gurion University of the Negev, Box 653, 84105 Beer-Sheva, Israel 


\section{Experimental}

ZSM5 and Na-A were prepared by the hydrothermal treatment described elsewhere ${ }^{2,3}$. SAXS measurements were performed using $\mathrm{Ni}$-filtered $\mathrm{Cu}$-Ka radiation (sealed tube generator), a compact Kratky camera (A. Paar) and a linear position-sensitive detector (Raytech). Sample-to-detector distance was $264 \mathrm{~mm}$, and exposure time was about 5 hours. Background scattering due to water was deducted by subtracting a constant value of the intensity measured at high scattering angles.

\section{Results and discussion}

Scattering curves of mother liquor samples of ZSM5 containing all the reaction ingredients at five different heating times are shown in Figure $1(\mathrm{a}) . \mathrm{I}(\mathrm{h})$ is the scattered intensity as a function of the scattering vector, $\mathrm{h}(\mathrm{h}=2 \pi \sin (\theta) / \lambda)$, where $2 \theta$ is the scattering angle and $\lambda$ the wave length. $\mathrm{t}=0$ is defined as the time before heating the solution mixture, after two hours of rigorous mixing of the ingredients at room temperature.

A broad shoulder appears around $\mathrm{h}=1.2 \mathrm{~nm}^{-1}$, denoted by an arrow. This shoulder is an indication of a characteristic dimension in the structure. As the reaction progresses, the shoulder shifts to lower $h$ values, and disappears completely after 2 hrs. Since scattering curves represent information in reciprocal space, the shift of the shoulder to lower $h$ values represents a growth process. The slope of the scattering curve at the $h \rightarrow 0$ limit (Guinier region) increases with the progression of the reaction. indicating an increase in the radius of gyration of the particles with heating time. Similar shift of the shoulder to lower $h$ values was also found in the Na-A zeolite during the first four minutes

Further structural analysis of the scuttering curves was obtained by employing a Fourier transform of the scattering data by the ITP method ${ }^{4}$ (Indirect Fourier Transform to calculate $p(r)$ ) to calculate the distance distribution function, $p(r)$. The scattered intensity is related to the structural elements by a Fourier transform ${ }^{5}$ :

(1) $I(h)=4 \pi \int_{0}^{\infty} \gamma(r) \frac{(\sin h r)}{h r} r^{2} d r$, where $\mathrm{r}$ is a relative distance, and $\gamma(\mathrm{r})$ is the correlation function of the electron density distribution, defined as:

(2) $\gamma(r)=\int_{0}^{\infty}\left[\rho\left(r^{\prime}\right)-\bar{\rho}\right]\left[\rho\left(r^{2}+r\right)-\bar{\rho}\right] 4 \pi r^{2} d r^{\prime}$,

where $\rho(r)$ is the the local density at a distance $r$ from a referece point, and $\bar{\rho}$ is the average density.

$p(r)$ can now be defined as:

(3) $p(r)=r^{2} \gamma(r)$

The ITP method provides accurate calculation of $p(r)$ from the measured scattering data. It can be applied only to scattering curves from dilute particle systems, and therefore can be used to evaluate the structural units in the mother liquor. In particular, globular, cylindrical or lamellar structures have distinctly different characteristic shapes of their $p(r)$ functions. The dimensions of the structural units are directly evident from the $p(r)$ function ${ }^{4}$

The distance distribution function, $\mathrm{p}(\mathrm{r})$, for ZSM5 zeolite at different times of heating are shown in Figure 1(b), as calculated by the ITP method from the scattering curves of the mother liquor. $p(r)$ at 
$t=0$ is a function characteristic of a solid globular unit with a uniform electron density. The diameter is indicated by the largest $r$ value for which $p(r)=0$. This suggests that $5 \mathrm{~nm}$ spheres, which we termed globular structural units, exist in the solution at $\mathrm{t}=0$. This result is supported by cryotransmission electron microscopy measurements ${ }^{6}$.

After 1 hour of heating, $p(r)$ was characteristic of a cylindrical aggregate. The length of the cylinder is indicated by the largest $r$ for which $p(r)=0$, and the diameter is approximated by the inflection point following the maximum in $p(r)$. A length of $22 \mathrm{~nm}$ is obtained after one hour, and increases to $44 \mathrm{~nm}$ after another hour of heating (Figure 1(b)).

Having established the elongated structure of the aggregate by its characteristic $p(r)$ function, a more accurate determination of its diameter is obtained by using the ITP method as applied to cylindrical bodies. In this case the distance distribution function of the cylinder cross-section, $P_{c}(r)$, is obtained. $P_{C}(r)$ was calculated for the mother liquor after 1 and 2 hours of heating. Diameter of 8 and $16 \mathrm{~nm}$ are obtained for these heating times from the distance where $\mathrm{P}_{\mathrm{c}}(\mathrm{r})->0$. After longer heating times no change in the distance distribution function was found. From geometry considerations, the cylinder found after one hour of heating may contain five globular structural units, as described in Figure 2(a). Since no change in the scattering pattern was found after reaction period longer then two hours, we assume that nucleation takes place during that time. The organic template is essential to the formation of aggregates. That was found by a control experiment in which the organic template, $\mathrm{TPA}^{+}$, was excluded from the reaction mixture. Only $2.5 \mathrm{~nm}$ globular particles were found by TTP, and no shift of the shoulder to lower $h$ values during the reaction was identified.

The same analysis procedure applied on the scattering curves of the $\mathrm{Na}-\mathrm{A}$ system, indicates the existence of $1 \mathrm{~nm}$ globular structural units upon mixing the ingredients. The short nucleation period of the Na-A zeolite ( 4 minutes) indicates rapid nucleation processes, that can not be time-resolved by the ITP method.

A model for the nucleation stage in the mother liquor during the nucleation stage of the ZSM5 zeolite is shown schematically in Figure 2(b). We suggest that globular structural units, with a diameter of 5 $\mathrm{nm}$, are formed in the mother liquor after mixing the reactants $(\mathrm{t}=0)$. These units aggregate to elongated particles as the reaction proceeds, reaching dimensions of of $8 \times 22 \mathrm{~nm}$ and $16 \times 44 \mathrm{~nm}$ after one and two hours of heating, respectively. The elongated units then settle to form a precipitate phase where further heating leads to formation of ZSM5 crystals.

Our results indicate a globular structural unit existing during the nucleation period of both template and a non-template zeolite synthesis.
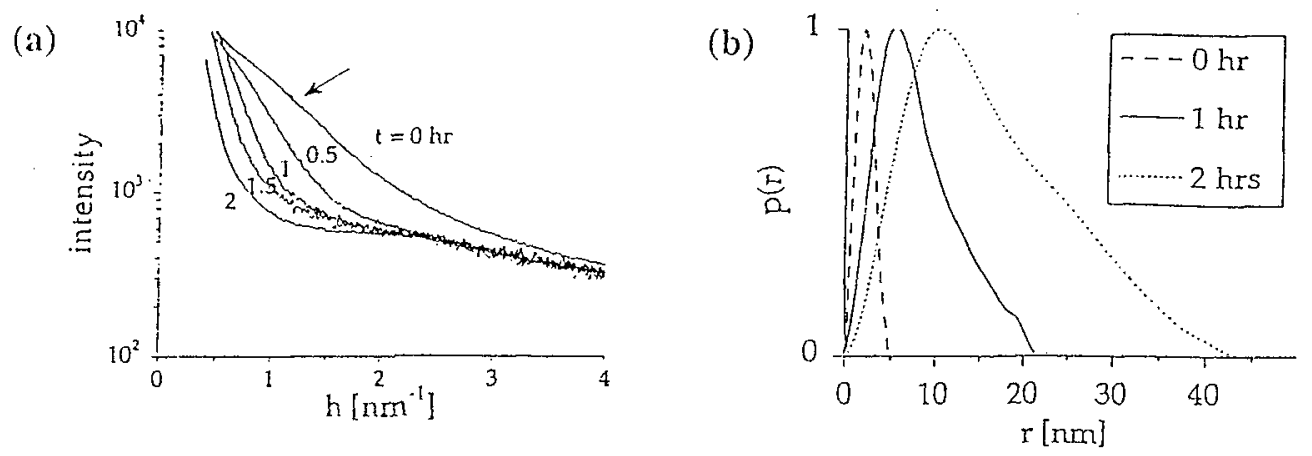

Figure 1: (a) Scattering curves of the ZSM5 mother liquor during the first two hours of heating; (b) distance distribution functions of a ZSM5 mother liquor during the first two hours of heating. 
(a)

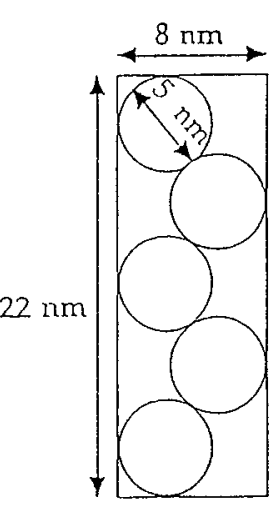

(b)
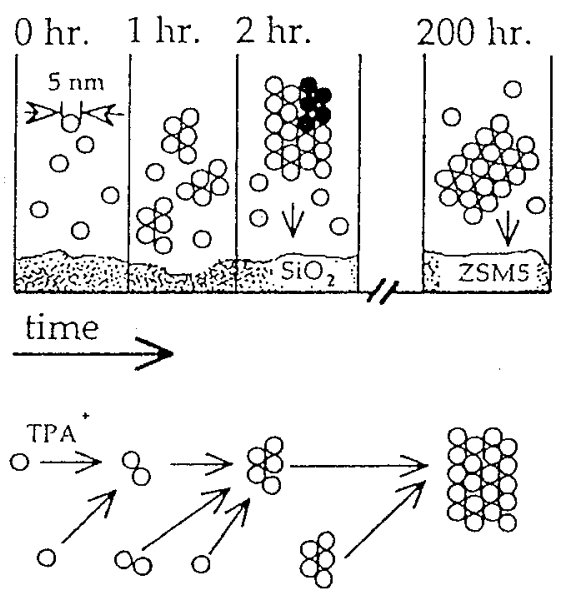

Figure 2: (a) A two-dimensional representation of the cylindrical aggregate of globular structural units; (b) a schematic representation of the nucleation process: globular structural units having a diameter of $5 \mathrm{~nm}$ are formed in the mother liquor upon mixing of the reactants $(t=0)$, and are agglomerated to elongated particles having dimensions of $8 \times 22 \mathrm{~nm}$ and $16 \times 44 \mathrm{~nm}$, after 1 and 2 hours, respectively.

\section{References}

[1] Van Santen, R.A., Keijsper, J., Ooms, G., Stud. Surf. Sci. Catal., (1988), 37, 65.

[2] Derouane, E.G., Detremmerie, S., Gabelica, Z., Blom, N., Appl. Cat., (1981), 1, 201.

[3] Ribeiro, F., NATO ASI series, Martinus Nijhoff Publishers, (1984).

[4] Glatter, O., J. Appl. Cryst., (1977), 10, 415.

[5] Glatter O., Kratky O., 'Small angle X-ray scattering', Academic press, London, (1982).

[6] Regev, O., Cohen Y., Kehat, E., Talmon Y., accepted for publication in Zeolite. 